\title{
Methadone Maintenance Treatment Program in Portuguese Community Pharmacies
}

\author{
Isabel JACINTO ${ }^{1}$, Anabela MADEIRA ${ }^{1}$, Cristina SANTOS $^{1}$, João GOULÃO ${ }^{2}$ and José PÁDUA ${ }^{2}$ \\ 1. Department of Pharmacy Services, National Association of Pharmacies (ANF), Lisboa 1249-069, Portugal \\ 2. Advisory Board, Institute on Drugs and Drug Addiction, I.P. (IDT, I.P.), Lisboa 1700-036, Portugal
}

Received: February 10, 2015 / Accepted: February 16, 2015 / Published: February 28, 2015.

\begin{abstract}
MMT (Methadone maintenance treatment) is an effective way to treat opioid dependence. In Portugal, an MMT program has been available in pharmacies since January 1998, when a formal agreement was signed by the IDT, I.P. (Institute on Drugs and Drug Addiction), the PPS (Portuguese Pharmaceutical Society), and the ANF (National Association of Pharmacies). In January 2004, the INFARMED (National Authority of Medicine and Health Products) became a partner of the program. The possibility of continuing the treatment at a community pharmacy was restricted to patients receiving a stabilized dose of methadone at IDT, I.P. treatment centers. Pharmacists joining the MMT were given mandatory training. Patients on the MMT program received daily doses of methadone solution under directly observed therapy, and were followed up by trained pharmacists. From January 1998 to January 2013, 3,090 patients underwent MMT in Portuguese community pharmacies. The delivery of MMT at community pharmacy level is feasible. This strategy improves access and adherence to methadone treatment, thus helping to reduce the use of illegal opioids. Community pharmacists fully demonstrated their ability to perform extended roles in public health and harm-reduction strategies. Interaction and close cooperation between the different health professionals and organizations involved were crucial to achieve adequate support to the patients.
\end{abstract}

Key words: Community pharmacy, directly observed therapy, methadone, pharmaceutical services, Portugal.

\section{Introduction}

Opioid dependence is a global health issue with implications at both personal and public health level. An estimated 16 million illegal opioid users are thought to exist worldwide. Treatment is multidisciplinary and involves psychological, social, and familial support. However, nowadays, the majority of treatment programs still rely on pharmacotherapy [1]. Once-a-day oral methadone hydrochloride prevents or substantially reduces the use of illicit opioids, such as heroin. Its primary function is to improve the well-being and the physical and mental health status of the opioid-dependent patient $[2,3]$. MMT is an effective way to treat opioid dependence, because it eliminates withdrawal symptoms and cravings for

Corresponding author: Isabel Jacinto, MSc in Pharmaceutical Sciences, pharmacist, research field: pharmacy services. E-mail: isabel.jacinto@anf.pt. heroin, blocks the euphoric effects of heroin, and avoids over-sedation $[2,3]$. MMT has also proved to decrease criminal activity associated with opioid dependence and to improve the patient's quality of life, with positive changes in health, employment, and social integration [2].

In Portugal - the setting of this study - illicit opioid use started increasing in the early 90s [4]; hence, there was a great demand for an MMT program that could grow close to the community. There are 2,885 community pharmacies in Portugal, making community pharmacies the most widely distributed health care providers across the country [5], with national coverage based on population distribution. The population's perception is that community pharmacies are trusty environments characterized by a highly qualified workforce and a large track record in promoting public health interventions (e.g., health risks 
assessments, diabetes management, and syringe/needle exchange).

Many countries, including Portugal, have encouraged the active participation of community pharmacists in MMT programs over the past recent years $[6,7]$. The implementation of such a program involves many stakeholders. In Portugal, health care needs for drug users are provided mainly through public services, namely the IDT, I.P. and the $\mathrm{MoH}$ (Portuguese Ministry of Health). Community pharmacies have long been partners of integrated response centers and IDT treatment teams on the administration of methadone, naltrexone, and buprenorphine. The treatment teams, composed of physicians, nurses, psychotherapists, and social workers, are outpatient units that act as the first point of contact with the treatment system. At this first stage, the patient's situation is assessed, a therapeutic objective is defined, and an implementation strategy is designed. Then, patients have access to individual and group therapy and to MMT (usually high threshold); other support services for patients and their families are also available (e.g., testing for infectious diseases, their treatment or referral, family therapy, and general health care) [8]. Community pharmacies cooperate actively with the treatment teams in methadone distribution and patient monitoring [4]. Such a tight collaboration has helped improve the quality of life of the patients, as they have the possibility to follow treatment in their area of residence or professional activity. This intervention represented a step forward toward providing social integration and privacy of the patients.

NGOs (Non-governmental organizations) and private entities may establish partnerships and agreements with public authorities to ensure treatment and recovery services [9]. The ANF is a private organization that represents the owners of as many as $98 \%$ of Portuguese community pharmacies, although membership is not mandatory. The mission of the ANF is to represent community pharmacies, to promote their economic sustainability and quality of service, and to stimulate the professional development of community pharmacists. ANF is also a negotiating partner with public authorities in policy matters regarding community pharmacies [10].

Therefore, in January 1998, IDT, I.P., the PPS (Portuguese Pharmaceutical Society), and ANF signed a formal agreement that aimed at implementing an MMT program in community pharmacies. In January 2004, the INFARMED (National Authority of Medicine and Health Products) became a partner of the program. The provision of the MMT in community pharmacies was based on DOT (directly observed therapy) with methadone provided by pharmacists to patients previously referred by treatment teams [4]. This was an unpaid service provided by community pharmacies and their pharmacists, who showed great social responsibility [10]. However, their involvement and scope in this program was beyond the administration of methadone and patient follow-up. Quality control of raw materials and the research and development of new formulations of methadone hydrochloride were also performed. These activities were carried out at ANF Laboratory of Pharmaceutical Sciences (Lisboa, Portugal) [4].

\section{Methods}

Pharmacists were invited to participate in an MMT program that targeted three main objectives for the patient: to improve adherence to treatment and quality of life; to increase chances of employment; and to reduce risky behaviors.

Pharmacists are highly skilled health professionals who hold a university degree (minimum of five years, including real-world training). However, in order to enroll in the program, ANF/IDT-sponsored training on drug abuse, its treatment, and DOT with methadone solution was mandatory [4]. All pharmaceutical interventions are summarized in a scheme showing the MMT intervention protocol at community pharmacies (Fig. 1).

Methadone hydrochloride solution $1 \%(9 \mathrm{~g} / 900 \mathrm{~mL})$ 
has special distribution requirements - which apply to no other medicine in Portugal. Therefore, the MMT program required a closed distribution system of methadone solutions, which was managed by IDT, I.P.: methadone was produced by the Military Laboratory (Portuguese Army, Lisboa, Portugal) and distributed by wholesalers directly to certified community pharmacies. Methadone stocks were kept locked in a safe vault at the community pharmacies [11]. Community pharmacy registry was managed by ANF according to the number of registered patients. All materials (e.g., pipettes, registry documents, takeaway bottles, and DOT plastic cups) and methadone solution were provided by IDT, I.P. [4].

The possibility of continuing MMT at a community pharmacy was restricted to patients receiving a defined, stabilized dose of methadone at IDT, I.P. treatment centers. All patients gave written informed consent prior to entering the program. In addition, a mutual expectations agreement was signed between patients and community pharmacies; the document provided guidelines for appropriate behavior at the pharmacy as a safe place for the patient, other patients, and the staff. Patient records were kept confidential [4, 11]. Each dose administration was recorded and signed by both pharmacist and patient to hold proof of dispensing and reception, respectively $[4,11]$. All MMT records filed at the community pharmacies were kept for at least five years as per the legal provisions of psychotropics [12].

The treatment team and the community pharmacist tailored a specific treatment plan to the needs and expectations of each individual patient $[4,6,11]$. Patients visited the community pharmacy on a daily basis for DOT with methadone. The pharmacist's role was to dispense an adequate and specific dose of methadone under DOT, to monitor potential illicit drug and alcohol consumption, to promote and track adherence, and to provide general support as well as encouragement $[11,13]$. The pharmacist could also prepare takeaway doses of methadone solution for self-administration. This task included dose-specific preparations, adequate labeling, and use of secure bottles (with child-resistant caps). Takeaway doses were available according to the treatment plan and narrowly dispensed to encourage patient compliance and prevent drug misuse [11]. Other tasks included patient education about MMT, namely methadone use, its potential adverse effects, toxicity, the importance of not missing a dose, especially during the early stages of treatment, and how and why doses are increased slowly. The community pharmacists acted in cooperation with the treatment teams to set timely reminders about patient appointments. By making daily visits to the pharmacy, the patients developed a close relationship of trust and confidence with the pharmacists [6].

To implement the MMT program, the community pharmacies were required to provide the following conditions: a safe health care setting; easy access; flexible and extended opening hours; a private area for patients to receive their daily methadone dose. The existence of a private area along with the provision of patient confidentiality and the care of no issues other than the medical ones promoted confidence and a close relationship with the pharmacist [14], which is the key for success [2].

Periodic multidisciplinary meetings were held between the community pharmacists, the treatment teams (physicians, nurses, therapists, and social workers), and the program manager from $\operatorname{ANF}[4,15]$. Those regular meetings focused on the monitoring and assessment of the patients (including results of urine tests and a proven track record of adherence to the appointments), clinical outcome, specific clinical cases, and overall MMT progress. Those meetings were also an opportunity to enroll new patients in the MMT program, to enroll new pharmacists in the training courses, and to support the engagement of new community pharmacies into the MMT program. Clinical information gathered by the community pharmacies about the patients undergoing MMT was shared among the physicians in order to promote adequate decisions regarding treatment plans (e.g., if 


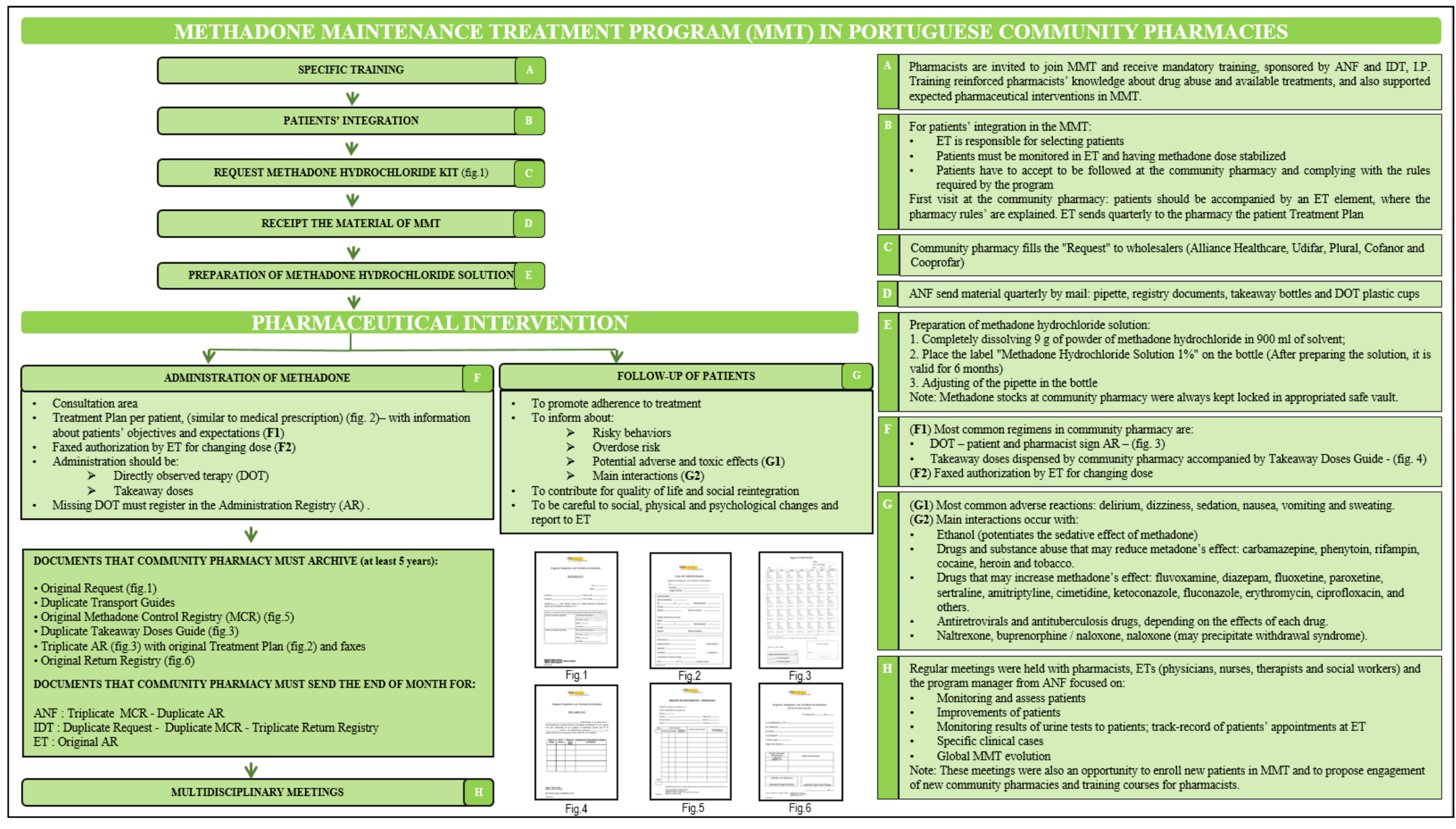

Fig. 1 Schematics of the MMT intervention protocol at community pharmacies. 
the physicians were unaware that one patient had missed a few methadone doses, it could lead to inadequate dosing based on complaints due to withdrawal symptoms [6]). Information included methadone doses dispensed, takeaway status, compliance with the treatment plan, and changes in patient behavior [4].

MMT data sent by pharmacists to ANF were inserted in the Metadona application (Microsoft Visual basic 6.0 and Microsoft SQL Server 7.0). Descriptive statistical analysis included absolute and relative counts. Continuous variables were summarized using central tendency measures. Analysis was performed using Microsoft Excel 97-2003 version.

\section{Results}

From January 1998 to January 2013, 3,090 patients enrolled on MMT programs at community pharmacies in Portugal (Fig. 2). In total, 792 pharmacists received specific training on treatment and DOT with methadone solution; 506 community pharmacies participated in the program, of which 222 (44\%) had 761 patients on follow-up [8].

From January 1998 to January 2013, 2,329 patients left the program, with 244 (10\%) being discharged after successfully completing their treatment with progressive dose reduction. Approximately half of the patients abandoned the program because they were no longer eligible for follow-up at the pharmacy or because they had moved to a different location (Fig. 3).

Thirty-eight treatment teams cooperated with the community pharmacies involved (Fig. 4).

The characteristics of the community pharmacies (access, quality, and proximity) and of the pharmacists (qualification, trust, and confidentiality) led to successful recovery of the patients, namely by promoting an inclusive lifestyle nearby the patient's home and/or workplace.

From January 1998 to January 2013, the majority of the patients (2354/3090 [76\%]) were male (Fig. 5).

Many of the patients (1049) were $>46$ years old (Fig. 6).

Patients stayed in the program an average of 36 months (Fig. 7). The time of permanence in the program was relevant to measure success based on pharmacist-patient relationships and the opportunity to undertake the planned activities.

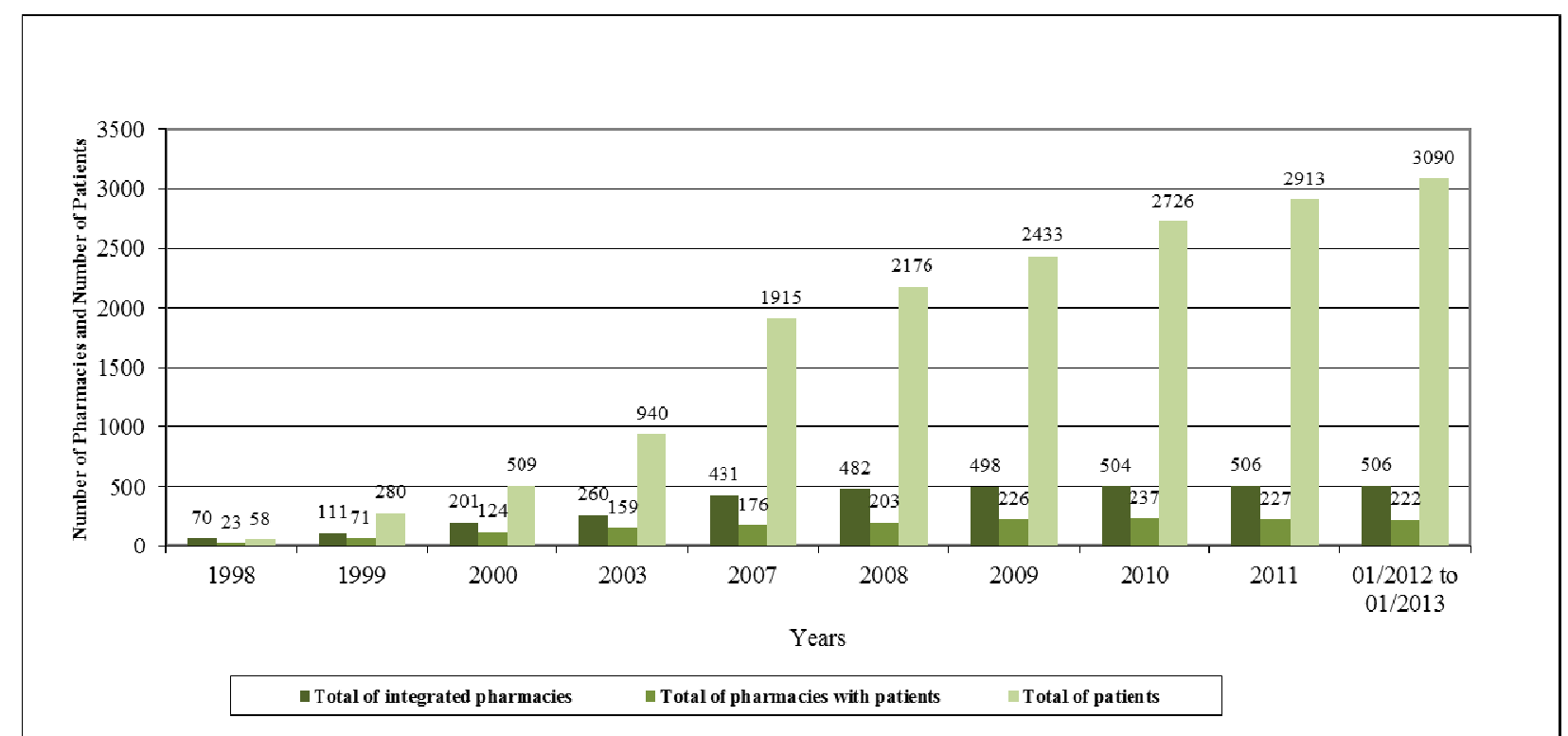

Fig. 2 Cumulative number of community pharmacies and patients involved in the MMT program from January 1998 to January 2013. 


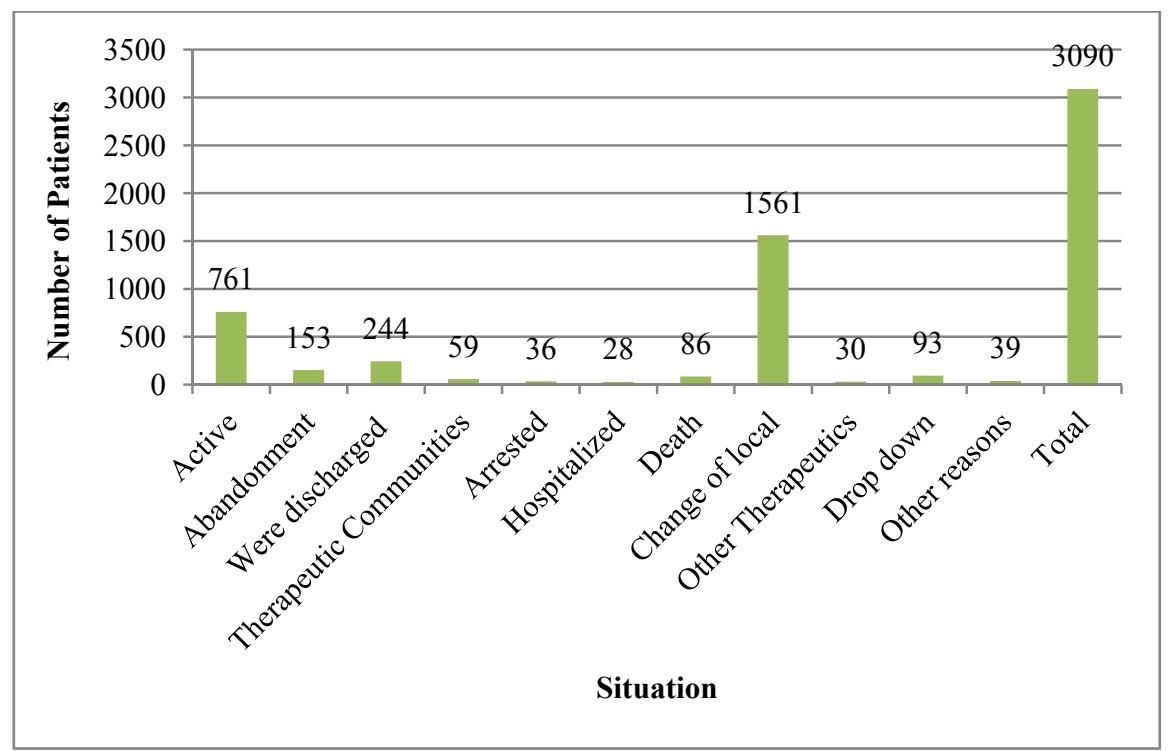

Fig. 3 Reasons for leaving the MMT program.

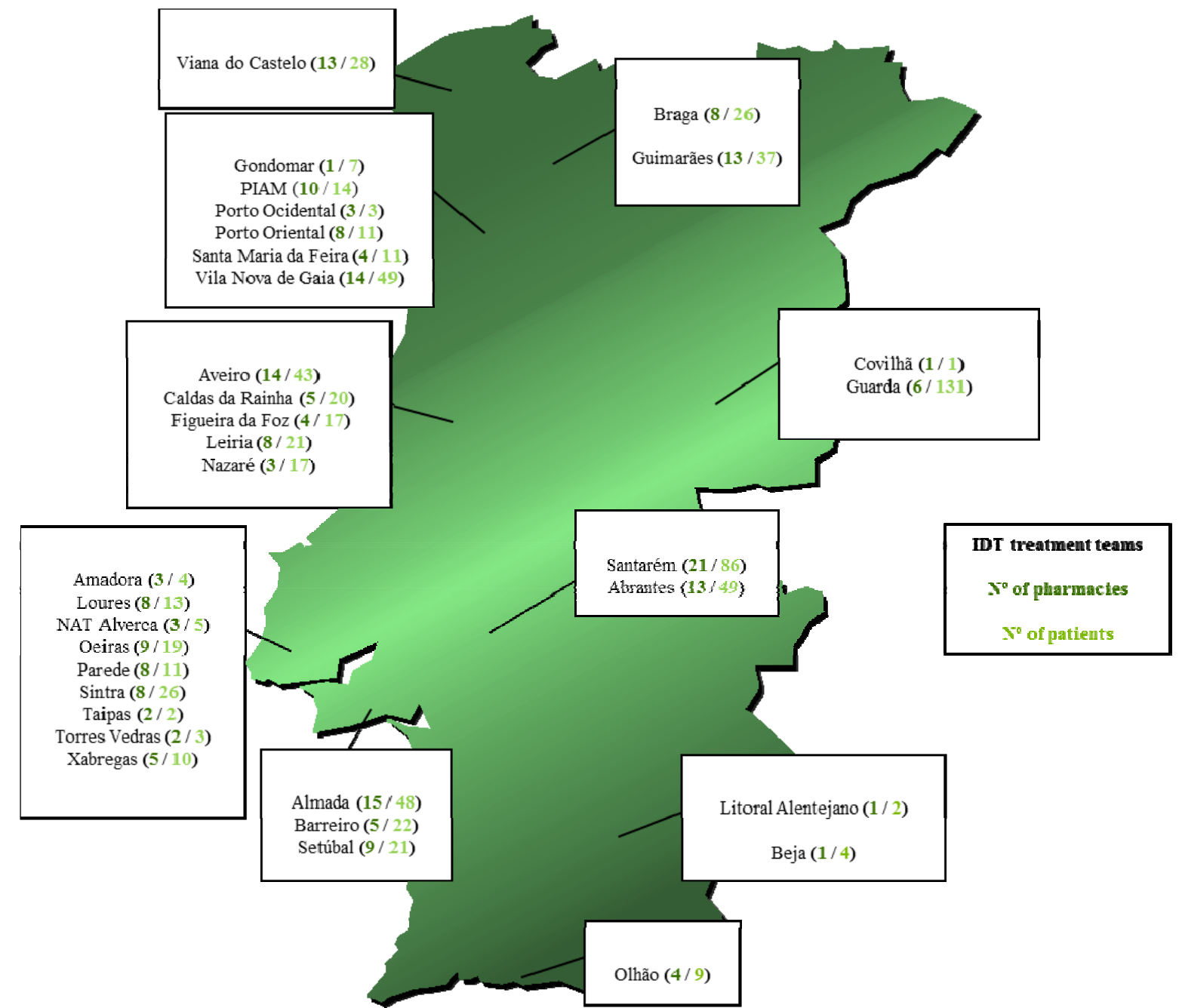

Fig. 4 Number of treatment teams that cooperated with the community pharmacies involved in the MMT program (data from January 2012 to January 2013). 


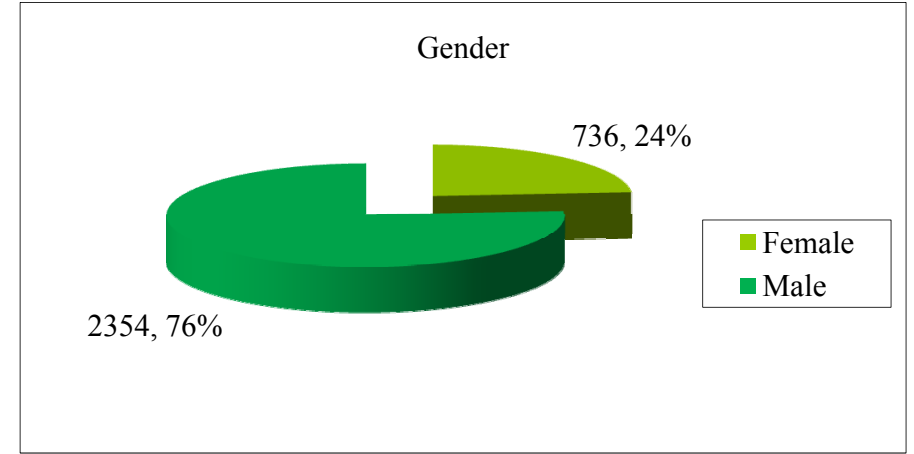

Fig. 5 Distribution of patients by gender.

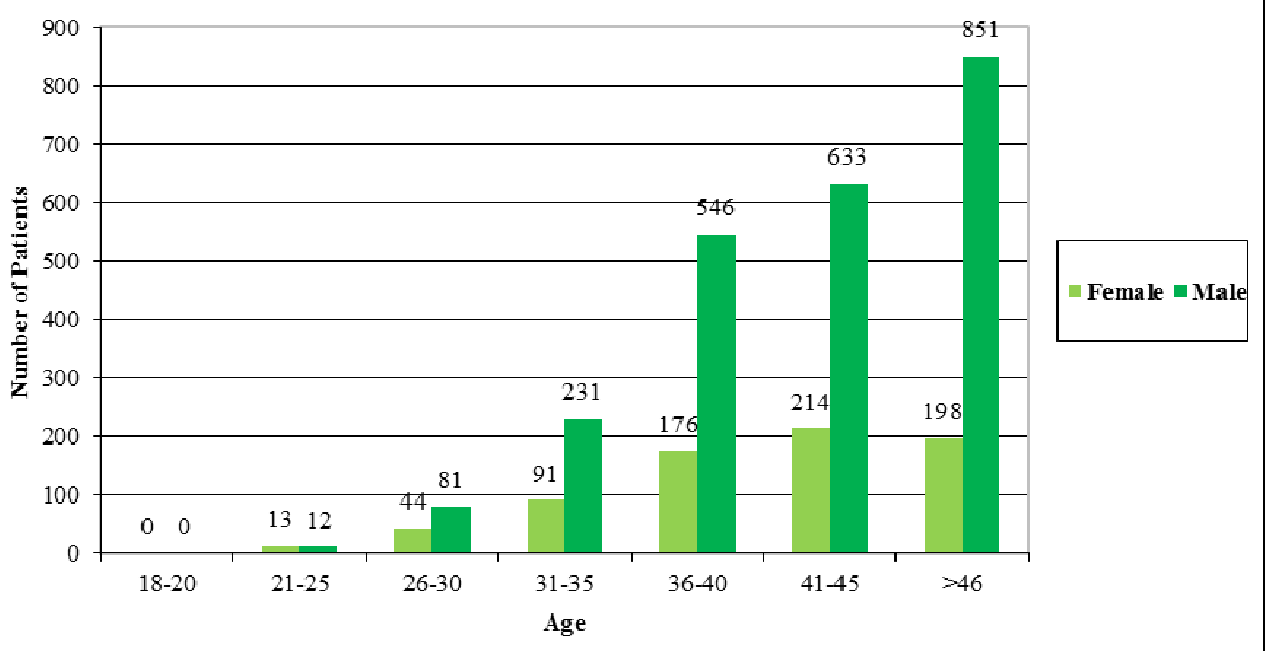

Fig. 6 Distribution of patients by age and gender.

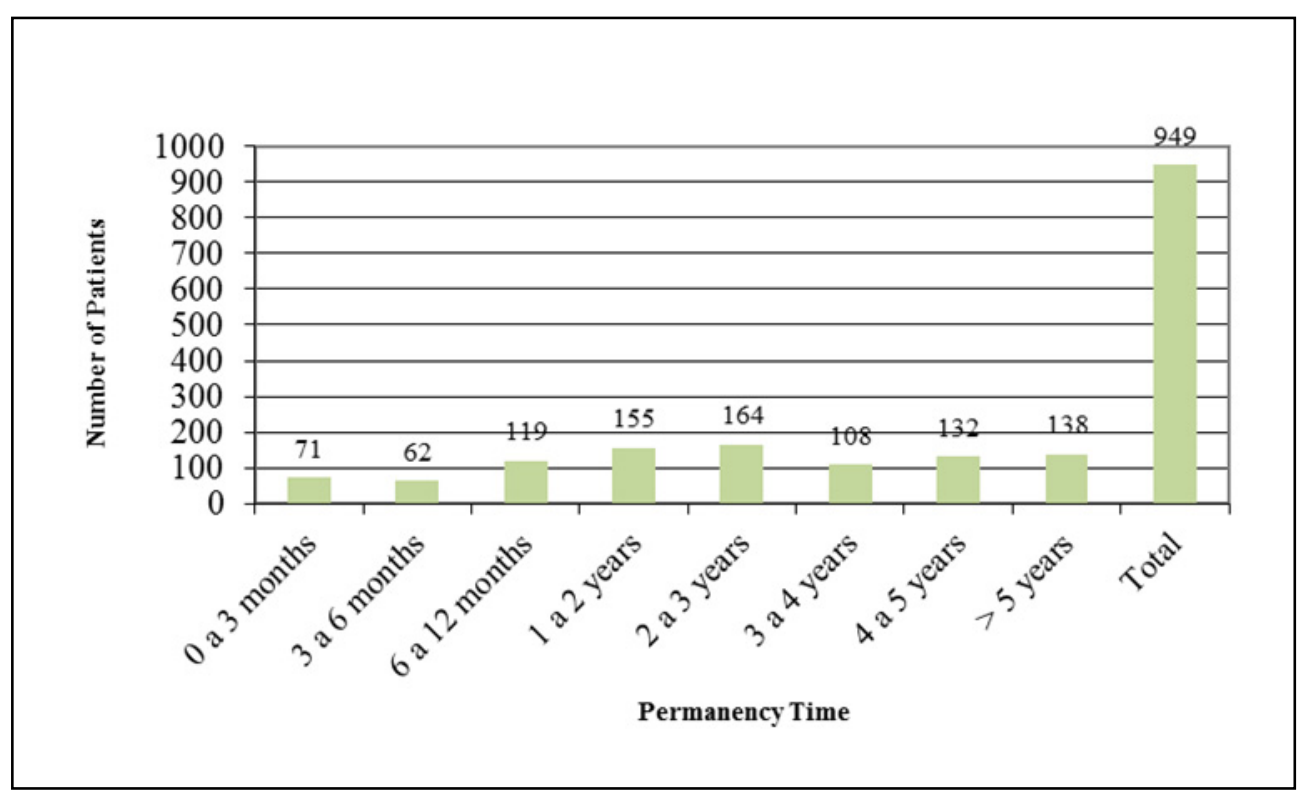

Fig. 7 Permanence in the MMT program. 


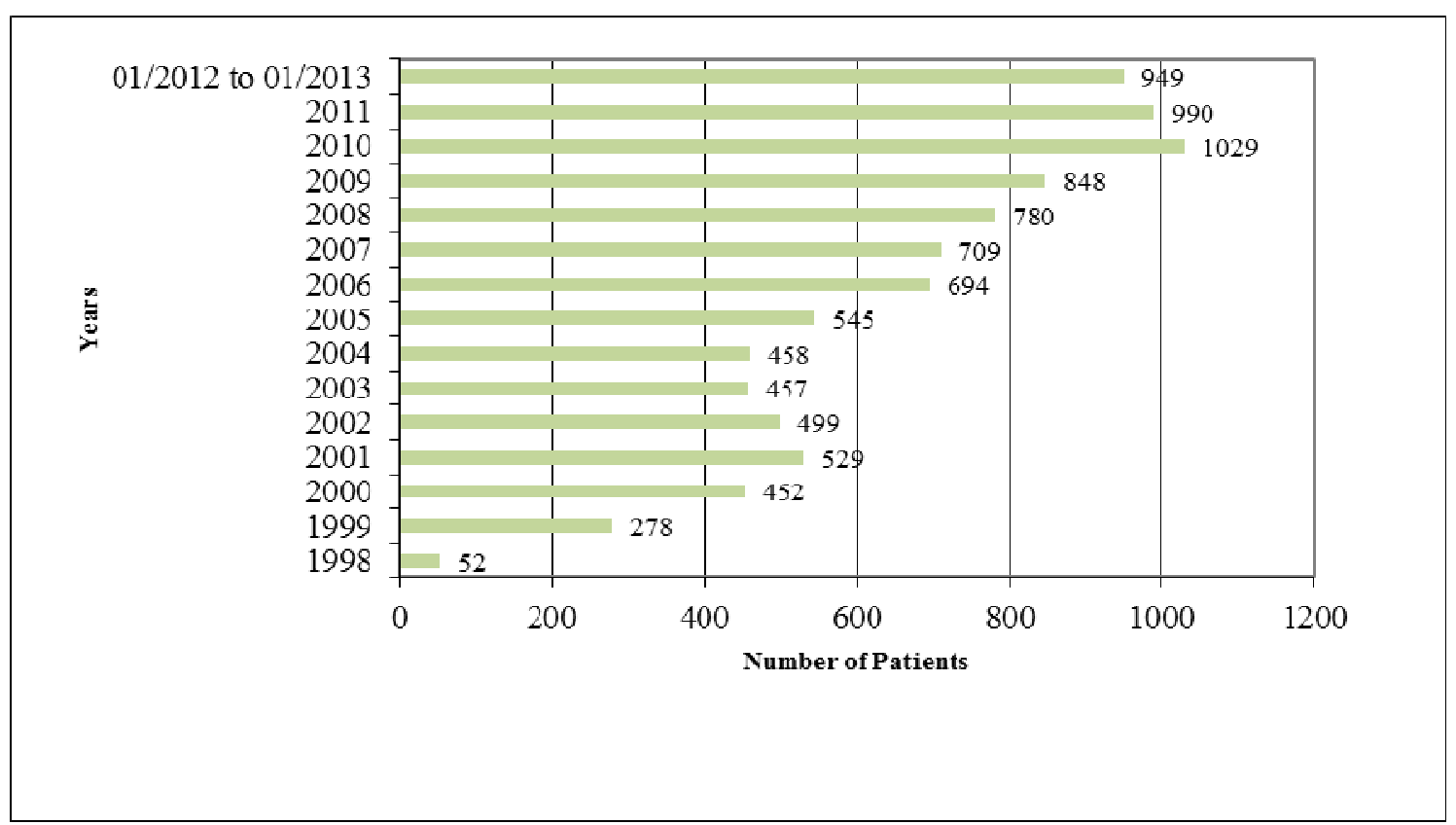

Fig. 8 Number of patients visiting the community pharmacies each year.

Between January 2012 and January 2013, 949 patients visited the community pharmacies (where they received at least one dose) within the context of the MMT program (Fig. 8). Each pharmacy followed up an average of four patients.

\section{Discussion}

In December 2012, a wide reform of the public administration system let to a reshape of the organizational structure of public intervention for drug addiction. Therefore, IDT, I.P. was extinct and its activities were split at two levels: strategic planning, monitoring, and prevention were attributed to the new SICAD (General-Directorate for Intervention on Addictive Behaviors and Dependencies); and operational activities and treatment units were included in the existing ARS (Regional Health Administration) centers, which are in charge of most health care activities [8].

Over the past recent years, community pharmacies have changed dramatically, with hundreds of pharmacies struggling to survive in the face of an unprecedented crisis in the sector. These changes had a deep impact on the MMT program, hindering community pharmacies from providing the service based on anything but social responsibility. As a consequence, since January 2013, community pharmacies have been forced to cease their collaboration with the MMT program. From December 2012 to January 2013, community pharmacies with patients on follow-up have gradually promoted an adequate referral to treatment centers.

The undeniable relevance of MMT to public health, the accomplished results, and patient confidence in pharmacists support pharmacies' interest in rejoining these activities in the future.

In July 2014, MoH and ANF signed a framework agreement that aimed to develop adequate incentives for pharmacies to enhance their cooperation with public objectives [16]. This agreement establishes a plan of work covering several activities and programs, including the possibility of reactivating MMT at pharmacies. This agreement is also innovative in the sense that it establishes an independent evaluation of the services provided by community pharmacies, and assesses economic gains and health impacts. Based on the data of the present work, the value of pharmacy-based interventions could be measured and, therefore, could be considered in pharmacy gains in the future [16]. 


\section{Conclusions}

Community pharmacies in Portugal are easy to access and are widely distributed across the country. The population's perception is that community pharmacies are trusty environments where highly qualified pharmacists establish a close relationship with patients.

The delivery of MMT at community pharmacy level is feasible. This strategy improves access and adherence to methadone treatment, thus helping to reduce the use of illegal opioids. Flexibility and extended opening hours are known to encourage patient compliance to challenging treatments (typically characterized by daily sessions, DOT, and privacy issues) regardless of location (urban or rural) and economic status (low- or high-income population) [5, 10]. Additional professional qualification helps community pharmacists play extended roles toward public health objectives [17].

\section{Acknowledgements}

The authors gratefully acknowledge all community pharmacists who participated in the program. We thank Humberto Martins, Rute Horta, Rita Santos, Ana Nogueira and Inês Miranda (ANF) for their support and remarks on a draft of this paper. The implementation of the MMT program at community pharmacies was funded by ANF.

\section{References}

[1] Julião, M., Medina, D., Fareleira, F, Costa, J., and Vaz Carneiro, A. 2013. Norma de Orientação Clínica para o Tratamento Farmacológico da Dependência Opiácea. Lisboa: Faculdade de Medicina da Universidade de Lisboa. Accessed January 3, 2015. http://www.cembe.org/avc/pt/docs/NOC\%20Tratamento $\% 20$ Depend $\%$ C3\%AAncia\%20Opi\%C3\%A1 cia\%20CE MBE\%202013.pdf.

[2] Verster, A., and Buning, E. 2000. Methadone Guidelines. The Netherlands: Euromethwork. Accessed December 28, 2014.

http://www.vad.be/media/124853/european\%20methadon e\%20guidelines.pdf.

[3] Patrício, L. 2009. Tratamento da Dependência de Heroína
-A Manutenção Opióide. Abrantes: Author's Edition.

[4] IDT (Instituto da Droga e da Toxicodependência), INFARMED (Instituto Nacional da Farmácia e do Medicamento), OF (Ordem dos Farmacêuticos) e ANF (Associação Nacional das Farmácias). 2004. Protocolo de colaboração entre o Instituto da Droga e da Toxicodependência, o Instituto Nacional da Farmácia e do Medicamento, a Ordem dos Farmacêuticos e a Associação Nacional das Farmácias no âmbito do Programa Terapêtico de Administração de Metadona. Lisboa.

[5] PGEU (Pharmaceutical Group of the European Union). 2013. Community Pharmacy, the Accessible Local Healthcare Resource-Annual Report. Accessed December 26, 2014. http://www.pgeu.eu/en/downloads/2336.html

[6] Isaac, P., and Sproule, B. 2009. Methadone Maintenance Treatment: Recommendations for Enhancing Pharmacy Services. Ontario, Canada: Centre for Addiction and Mental Health. Accessed December 28, 2014. http://knowledgex.camh.net/policy_health/substance_use/ mmt_enhancing_pharmacy_services/Documents/mmt_en hancing_pharmacy_services.pdf.

[7] Chaar, B., Hanrahan, J., and Day, C. 2011. "Provision of Opioid Substitution Therapy Services in Australian Pharmacies." Australasian Medical Journal 4 (4): 210-6.

[8] EMCDDA (European Monitoring Centre for Drugs and Drug Addiction) and SICAD (Serviço de Intervenção nos Comportamentos Aditivos e nas Dependências). 2013. National Report (2012 Data) to the EMCDDA by the Reitox National Focal Point. "Portugal": New Developments, Trends and In-Depth Information on Selected Issues. Lisboa. Accessed December 27, 2014. http://www.emcdda.europa.eu/attachements.cfm/att_2284 94_EN_2013_Portugal\%20National\%20report.pdf.

[9] European Monitoring Centre for Drugs and Drug Addiction. 2014. Drug Treatment Overview for Portugal. Lisboa: EMCDDA. Accessed December 22, 2014. http://www.emcdda.europa.eu/data/treatment-overviews/ Portugal.

[10] Costa, S., Santos, C., and Silveira, J. 2006. "Community Pharmacy Services in Portugal." The Annals of Pharmacotherapy 40 (12): 2228-34.

[11] GUILD (The Pharmacy Guild of Australia). 2006. Opioid Substitution Program: Resource Manual Standard 3 Delivery of Health Programs and Services. New South Wales: The Pharmacy Guild of Australia. Accessed January 3, 2015. http://www.guild.org.au/docs/default-source/nsw-branchpublic/professional-services/dependency-care/pharmacot herapy/opiod-substitution-resource-manual.pdf?sfvrsn $=0$

[12] D.R. I Série - A. 1993. Decreto-Lei n. ${ }^{\circ} 15 / 93$. Artigo 16. ${ }^{\circ}$. 
Accessed $\quad$ February 24, 2015. https://www.infarmed.pt/portal/page/portal/INFARMED/ LEGISLACAO/LEGISLACAO_FARMACEUTICA_CO MPILADA/TITULO_III/TITULO_III_CAPITULO_III/0 68-DL_15_93_VF.pdf.

[13] Joint Working Group of the National Pharmaceutical Forum/Scottish Medical and Scientific Advisory Committee. 2005. Prevention and Treatment of Substance Misuse. Delivering the Right Medicine: A Strategy for Pharmaceutical Care in Scotland. Edinburgh: Scottish Executive. Accessed January 3, 2015. http://www.scotland.gov.uk/Resource/Doc/57346/001700 2.pdf.

[14] Caulfield, J. 2009. "Opioid Replacement Therapy-A Rewarding Challenge for Community Pharmacy." Australian Pharmacist 28 (9).

[15] EMCDDA (European Monitoring Centre for Drugs and Drug Addiction) and IDT (Instituto da Droga e da Toxicodependência, I.P.). 2011. National Report (2010 Data) to the EMCDDA by the Reitox National Focal Point. "Portugal": New Developments, Trends and In-depth
Information on Selected Issues. Lisboa. Accessed December 27, 2014. http://www.emcdda.europa.eu/html.cfm/index142533EN. html.

[16] MoH (Ministério da Saúde) and ANF (Associação Nacional das Farmácias). 2014. Acordo entre o Ministério da Saúde e a Associação Nacional das Farmácias sobre a Implementação de Programas de Saúde Pública. Lisboa. Accessed July 10, 2014. http://www.infarmed.pt/portal/page/portal/INFARMED/ MAIS_NOVIDADES/Acordo_MS_ANF_09_\%2007_20 14.pdf.

[17] Walker, M. 2006. Best Practice Guidance for Commissioners and Providers of Pharmaceutical Services for Drug Users. London: Royal Pharmaceutical Society of Great Britain, Pharmaceutical Services Negotiating Committee, Pharmacy Misuse Advisory Group and NHS (National Treatment Agency for Substances Misuse). Accessed December 26, 2014. http://archive.psnc.org.uk/publications_download.php/92/ Pharmaceutical20services20for20drug20users.pdf. 